\title{
Modeling of Energy-Efficient Factories with Flow System Theory
}

\author{
Hendrik Hopf and Egon Müller \\ Department of Factory Planning and Factory Management \\ Institute of Industrial Sciences and Factory Systems \\ Chemnitz University of Technology \\ Chemnitz, Saxony, 09107, Germany \\ \{hendrik.hopf, egon.mueller\} amb.tu-chemnitz.de
}

\begin{abstract}
Energy and resource efficiency have become important objectives for industrial processes. They are taking more and more impact on the competitiveness of companies. Therefore, energy-efficient factory systems are needed in terms of sustainable production. Thus, new or improved models, methods and tools focusing energy efficiency are necessary. In this paper, the "Flow System Theory", as a tool for modeling technical systems and processes, is presented. It is extended in order to describe the energy flow systems of factories. This is supposed to be the basis for systematic modeling of energy-efficient factory systems.
\end{abstract}

Keywords: Energy Efficiency, Factory Modeling, Energy Flow Systems.

\section{Introduction}

Increasing demand for raw materials and the depletion of non-renewable resources lead to scarcity and uncertain availability of resources. Raw material and energy prices continue to rise in the future. Climate policy objectives such as the reduction of global $\mathrm{CO}_{2}$ emissions and the expansion of renewable energy should counteract these developments. Besides cost, time and quality, energy and resource efficiency are more and more considered in business activities. It is not only an environmental contribution due to political, social and ecological challenges [1]. These objectives influence increasingly the competitiveness. The industrial sector causes about $30 \%$ of the energy consumption in Germany, whereas the most of it is used for process heat and mechanical energy [2]. By improving energy efficiency, direct cost savings and indirect environmental benefit can be achieved [3]. The saving potential through more efficient use of energy is estimated in different studies with $20-30 \%$ for industry, but it varies from company to company [4]. It should be noted that energy efficiency is recognized as an essential tool for energy savings. However, for instance, the "World Energy Outlook 2012" emphasizes that this potential is not yet exhausted [5].

In consequence, more research and development are necessary to design energyefficient systems and processes. 


\section{Methodical Planning of Energy-Efficient Factories}

The energy-efficient factory has become a new type of factory. It focuses on the manufacture of goods and services by minimal energy use and it emphasizes the energy flow [6]. Therefore, it includes energy-optimized systems and processes which are treated in their entirety with the complex coherences. Closed energy cycles of the factory contribute to the minimization of energy losses [7]. The energy-efficient factory is an active participant of the energy conversion chain. In addition, this factory integrates holistically the objective energy efficiency in the structural and procedural organization through Energy Management.

For the above-mentioned reasons, there are new requirements which lead to numerous new energy-related planning contents and volumes in different fields of action (e.g. building, building services or manufacturing) [8]. In this way, the complexity of this discipline rises. Therefore, there is a demand for new or improved models, methods and tools to support the planning participants.

For designing energy-efficient factories, a few scientific approaches have been developed in the last time.

The planning method for manufacturing processes in automobile industry by Engelmann concentrates the factory planning process on energy-related activities and includes action approaches (efficiency factor, reduced losses, recovery, substitution, dimensioning and mode of operation) for improving energy efficiency [9]. These approaches are expanded by including "sensitization" by Reinema et al. [10]. The "EnergyBlocks" planning methodology by Weinert et al. predicts the energy consumption of production systems basing on energy profiles of different operating states [11]. The "Peripheral Model" structures the systems of a factory according to the dependence on the production program, whereby the energy consumption can be traced to its origin backwards from the peripheral processes to the main processes [8]. The model for sustainable factories by Despeisse et al. aims at the interactions between manufacturing operations, supporting facilities and building with the help of material, energy and waste flows [12].

Besides, there are further methods and tools such as "Cumulative Energy Demand" [13], "Life Cycle Assessment" [14], "Material Flow Analysis" [15] or "Material Flow Cost Accounting" [16] which are not originally developed for factory planning, but can be used for specific activities (e.g. for analysis or evaluation). Energy flow visualization tools like Sankey diagrams support planning tasks, too. A popular example is also the "Energy Value Stream Mapping" (EVSM). It integrates energy aspects like energy key figures and design recommendations in the primary Value Stream Mapping [17-20]. The EVSM is a tool for energy-oriented analyzing and optimization of business processes and chains. However, the EVSM is not suitable for designing systems because of the specific principles of the Value Stream Mapping (e.g. process analysis based on a snapshot).

As a result, it was found that it is hardly possible to model factory systems with its elements, relations, items etc. considering energy efficiency with the help of existing methods and tools. 


\section{$3 \quad$ Modeling with Flow System Theory}

In factory planning the factory is interpreted as factory system through system theory approaches. Complex totalities and coherences are described with the help of systems thinking [21]. In general, the factory is a sociotechnical system including humans and technology. In this paper, the technical systems are focused. These systems are artificial constructions that are created to fulfill a specific purpose [22]. In the case of factories, this means the production of goods.

The "Flow System Theory" is a tool for modeling technical systems and processes [23-25]. Hereby, the factory as an entire system combines particular flow systems. They are mainly separated by the flow items material, information, energy as well as persons and capital. The flow systems consist of individual flow system elements (e.g. machines or facilities) which are passed by the flow items. Meanwhile, flow functions such as the basic functions transform, transport and store are executed as well as changes of property or state of the flow items or flow system elements are caused [25]. Thus, the Flow System Theory offers a suitable basis for describing the factory system with its elements, functions, relations and items. Therefore, in the following, this approach will be extended in order to describe energy flow systems of factories.

\section{Extension of Energy Flow Systems}

\subsection{Energy Flow Items, Functions, System Elements and Structures}

In general, terms of energy are specified by physical (e.g. anergy, exergy or forms of energy) technical (e.g. energy consumption, energy losses or waste heat) or economical (e.g. primary or secondary energy) aspects [26]. On the one hand, flow items of energy flow systems can be described by the energy forms such as mechanical energy or heat energy. On the other hand, energy carriers such as electricity, compressed air or water can be used. This means that these mediums are allocated to the energy flow although they belong to the material flow by system theory approaches. However, due to the good measurability of the energy carriers, it is an acceptable solution which is also often used in practice (e.g. metering of consumption by Energy Management).

The basic functions of system theory are usable for energy flow systems, too. Transform converts qualitatively and / or quantitatively the input into the output, while transport and store do not change the objects themselves, but moves them through space and time [22]. Based on that, specific technical functions of energy flows such as energy provision / input, generation, conversion, storage, transportation / distribution, utilization, recovery and emission / output are derived (based on [2630]). The flow functions are connected as chains or cycles.

The necessary technologies (e.g. generation or storage system) are derived from the flow items and the flow functions. The energy-relevant systems of the factory are classified in these types of technologies. In addition, these systems act as the so called flow 
system elements of the energy flow. It should be noted that the elements belong to different flow systems. This condition allows describing the object with its different functions. For example, primarily, a manufacturing machine is a part of the material flow, but it is also an energy consumer in the energy flow and an informationprocessing computer in the information flow. Thus, the system includes several major and minor functions. Furthermore, it is important to remember that each process and each flow system element needs energy for its performance. Therefore the material and information flows are always connected to energy flows [25]. Thus, the different flow systems are linked with each other through the flow system elements.

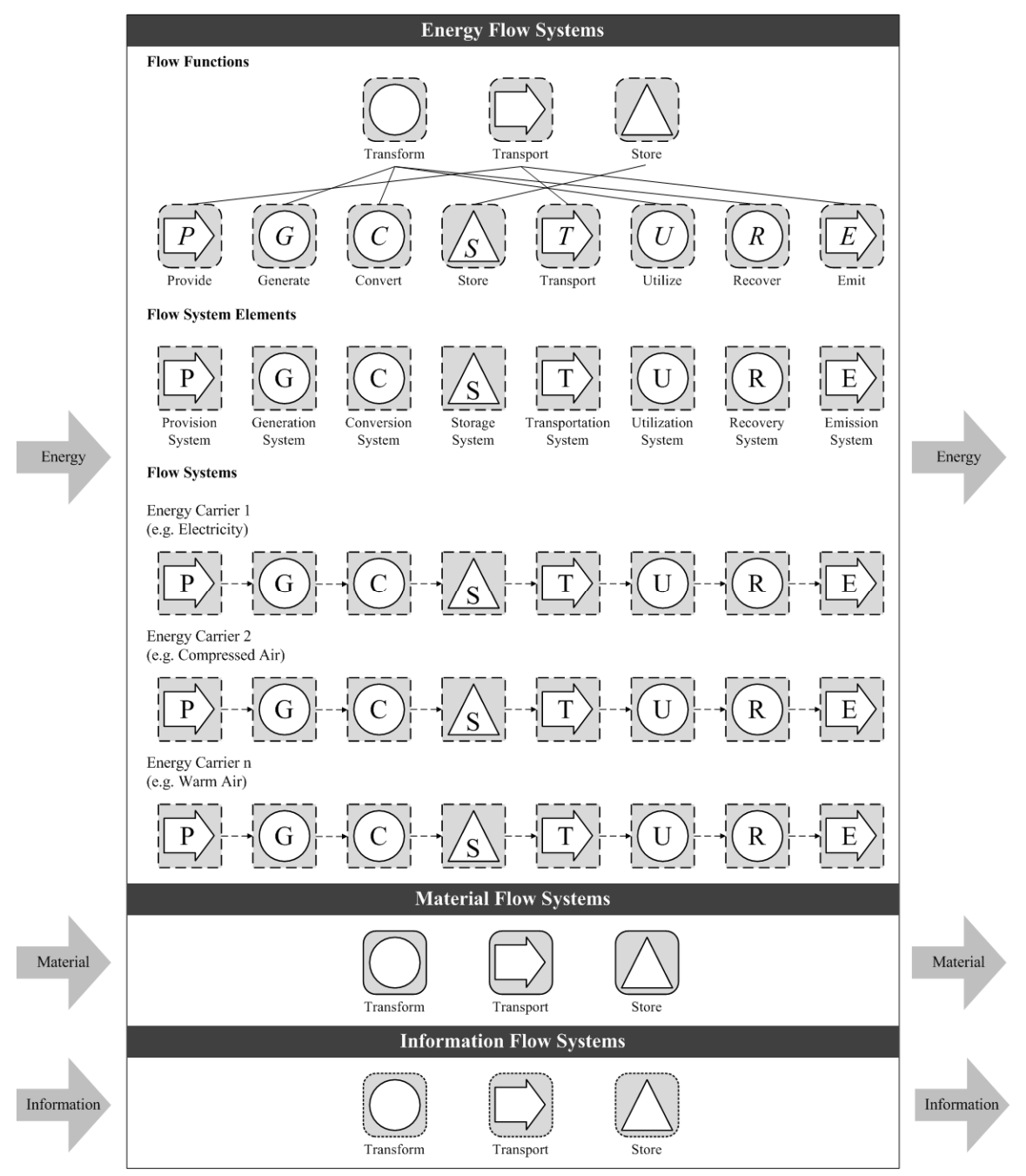

Fig. 1. Energy Flow Systems as Extension to [25] 
The flow items pass the flow system elements one after another which results in a chain of functions (processes). By this, the flow system elements are connected with each other in space and time. Different structures of flow systems are derived from that fact. In general, an energy conversion chain starts with the input of a source and ends with the output of a drain. Meanwhile, various transformation, transportation and storage steps are processed. The energy chains differ in the energy carrier and the structure of the factory system. For example, compressed air is usually generated inhouse whereas electricity comes mainly from outside. In context of energy efficiency, closed energy cycles (e.g. by energy recovery) are preferred. By this, the energy losses are minimized.

\subsection{Energy Flow Systems}

The classification of the energy flow systems belongs to the flow items. Therefore, basing on the necessary energy forms, the energy carriers of the processes are determined. The principle flow system from provision to emission can be set up for every energy carrier. However, it is also possible to separate the energy flow systems by energy forms (for physical description) or classes such as solids, liquids or gases. Figure 1 summarizes the energy flow functions, system elements and systems.

\section{$5 \quad$ Use Case}

The application of the Flow System Theory for modeling energy flow systems of a factory is illustrated in this section. The "Experimental and Digital Factory" (EDF) [31] is chosen as a simplified example. The EDF consists of various manufacturing, logistics and information systems of an item-based production. For example, figure 2 shows an assembly machine which needs electricity and compressed air and generates waste heat as byproduct. Therefore, different facilities such as the supply of electricity and compressed air as well as room lighting and heating are necessary for the operation of the machine and the other production systems. The structures of the flow systems are derived from the connection between the output of sources (e.g. air compressor) and the input of drains (e.g. tank) of the several energy flows.

The electricity is delivered in the building and distributed in several areas by distribution boxes. The compressed air and heat generation is in the same building but outside the production area. The room heat is provided by wall and ceiling radiators. The waste heat of machines and facilities has to be added, too. The interchange of warm and cold air between the building and its environment happens through the building envelope as well as through doors, gates and windows. In this case, the room is declared as energy user as drain of the generation of heat. However, it is also a heat converter, transporter and storage.

As an extension, by adding quantitative key figures (e.g. energy consumption per time period), inputs and outputs (balancing) as well as capacities and demands can be compared (not shown in figure 2). Hereby, weak spots such as bulk consumers as well as under-/overcapacities can be identified. 
For example, facilities such as building services are often oversized because of multiple safety factors. Moreover, in practice, there is often no adaption of the energy infrastructure after changing the production processes. However, this is very important to optimize the energy infrastructure like reducing energy losses by avoiding converting processes or oversized systems (e.g. transformers or compressors). These facts are important indicators for the energy efficiency-oriented determination of functions, dimensioning, structuring and designing of factory systems.
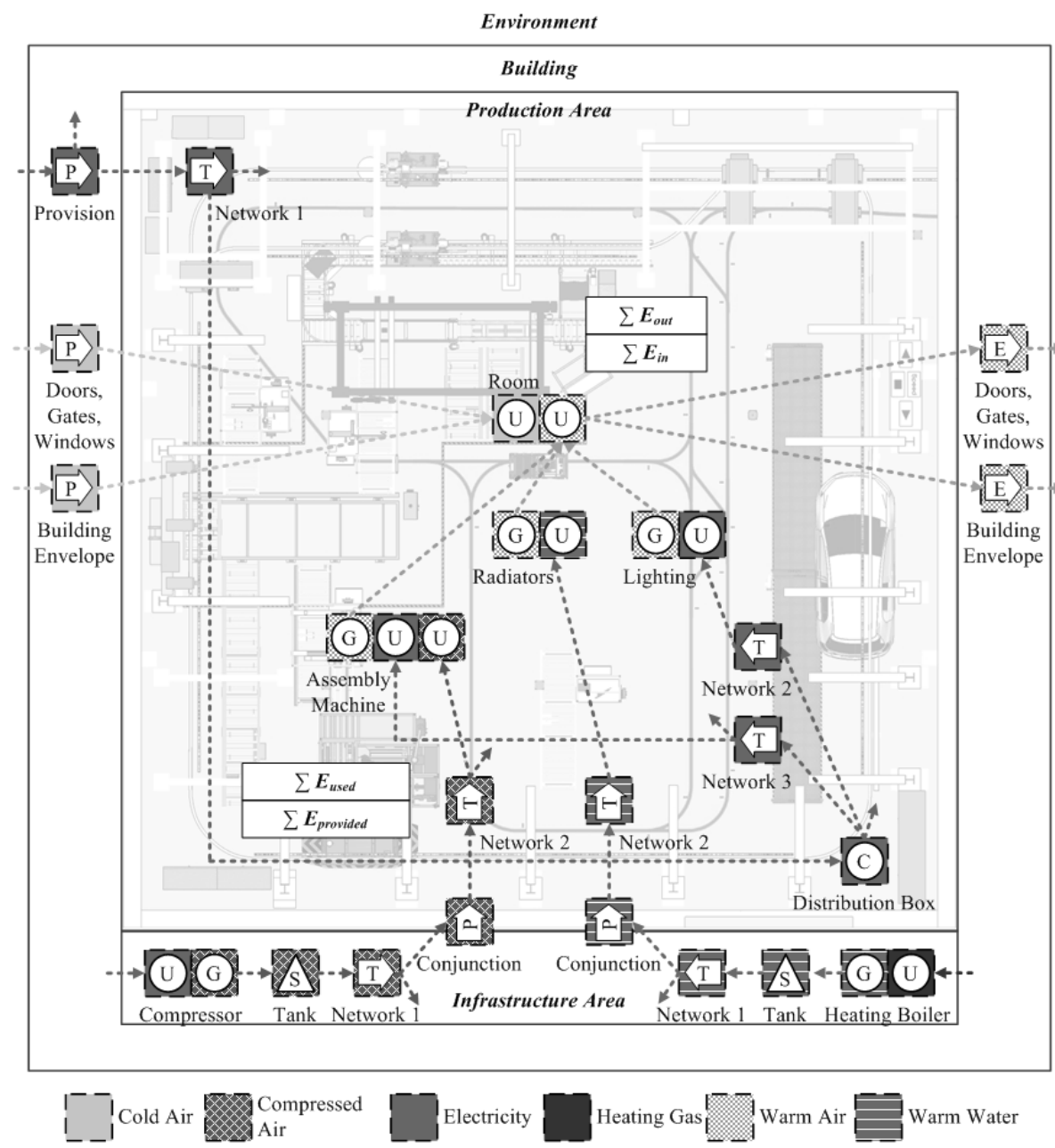
Heating Gas?: 1 Warm Air Warm Water

Fig. 2. Qualitative Model of the Energy Flow Systems of the Experimental and Digital Factory

As a result, the modeled factory creates transparency of the energy flow systems. It is the basis for the energy efficiency-oriented planning, analyzing and optimizing of the factory. Furthermore, other planning tools and methods such as energy flow visualizations with Sankey diagrams can build on it. 


\section{Summary}

Sustainable production depends on energy and resource-efficient factory systems. Therefore, adequate models, methods and tools are necessary for factory planning. In this paper, the extension of the "Flow System Theory" and the qualitative description of energy flow systems are presented. As a result, the presented approach offers a suitable basis for the description of factory systems with their elements, relations and items. This is supposed to be the starting point for systematic modeling of energyefficient factory systems and for further planning, analyzing and optimization activities. Currently, the energy-relevant key figures are specified and evaluated for the quantitative modeling of factory systems (see also [32]). Further on, the approach is tested and validated in other practical use cases.

Acknowledgements. The Cluster of Excellence "Energy-Efficient Product and Process Innovation in Production Engineering" (eniPROD ${ }^{\circledR}$ ) is funded by the European Union (European Regional Development Fund) and the Free State of Saxony.

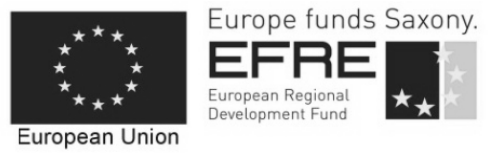

\section{References}

1. Nyhuis, P.: Ressourceneffizienz im Fokus. wt Werkstattstechnik Online 101, 179 (2011)

2. Federal Ministry of Economics and Technology: Energiedaten - nationale und internationale Entwicklung,

http://www.bmwi.de/DE/Themen/Energie/energiedaten.html

3. Jeon, H.W., Prabhu, V.V.: Modeling Green Fabs - A Queuing Theory Approach for Evaluating Energy Performance. In: Emmanouilidis, C., Taisch, M., Kiritsis, D. (eds.) APMS 2012, Part I. IFIP AICT, vol. 397, pp. 41-48. Springer, Heidelberg (2013)

4. Hesselbach, J.: Energie- und klimaeffiziente Produktion - Grundlagen, Leitlinien und Praxisbeispiele. Vieweg+Teubner, Wiesbaden (2012)

5. International Energy Agency: World Energy Outlook 2012, - Executive Summary (2012), http: / / www.worldenergyoutlook.org/publications/weo-2012/

6. Wirth, S., Schenk, M., Müller, E.: Fabrikarten, Fabriktypen und ihre Entwicklungsetappen. ZWF Zeitschrift für wirtschaftlichen Fabrikbetrieb 106, 799-802 (2011)

7. Neugebauer, R.: Forschung für die Produktion in Deutschland - Maximale Wertschöpfung aus minimalen Ressourceneinsatz. In: 3. Kongress Ressourceneffiziente Produktion, Leipzig (2013)

8. Müller, E., Engelmann, J., Löffler, T., Strauch, J.: Energieeffiziente Fabriken planen und betreiben. Springer, Heidelberg (2009)

9. Engelmann, J.: Methoden und Werkzeuge zur Planung und Gestaltung energieeffizienter Fabriken. TU Chemnitz, Chemnitz (2009)

10. Reinema, C., Schulze, C.P., Nyhuis, P.: Energieeffiziente Fabriken - Ein Vorgehen zur integralen Gestaltung. wt Werkstattstechnik Online 101, 249-252 (2011) 
11. Weinert, N., Chiotellis, S., Seliger, G.: Methodology for planning and operating energyefficient production systems. CIRP Annals - Manufacturing Technology 60, 41-44 (2011)

12. Despeisse, M., Ball, P.D., Evans, S., Levers, A.: Industrial ecology at factory level - a conceptual model. Journal of Cleaner Production 31, 30-39 (2012)

13. The Association of German Engineers (VDI): VDI 4600: Cumulative energy demand (KEA) - Terms, definitions, methods of calculation. Beuth, Berlin (2012)

14. International Organization for Standardization: ISO 14040: Environmental management Life cycle assessment - Principles and framework (2009)

15. Tschandl, M., Posch, A.: Integriertes Umweltcontrolling - Von der Stoffstromanalyse zum Bewertungs- und Informationssystem. Gabler, Wiesbaden (2012)

16. International Organization for Standardization: ISO 14051: Environmental management Material flow cost accounting - General framework (2011)

17. Erlach, K., Westkämper, E.: Energiewertstrom - Der Weg zur energieeffizienten Fabrik. Fraunhofer, Stuttgart (2009)

18. Reinhart, G., Karl, F., Krebs, P., Maier, T., Niehues, K., Niehues, M., Reinhardt, S.: Energiewertstromdesign - Ein wichtiger Bestandteil zum Erhöhen der Energieproduktivität. wt Werkstattstechnik Online 101, 253-260 (2011)

19. Bogdanski, G., Schönemann, M., Thiede, S., Andrew, S., Herrmann, C.: An Extended Energy Value Stream Approach Applied on the Electronics Industry. In: Emmanouilidis, C., Taisch, M., Kiritsis, D. (eds.) APMS 2012, Part I. IFIP AICT, vol. 397, pp. 65-72. Springer, Heidelberg (2013)

20. Schillig, R., Stock, T., Müller, E.: Energiewertstromanalyse - Eine Methode zur Optimierung von Wertströmen in Bezug auf den Zeit- und den Energieeinsatz. ZWF Zeitschrift für Wirtschaftlichen Fabrikbetrieb 108, 20-26 (2013)

21. Haberfellner, R., de Weck, O., Fricke, E., Vössner, S.: Systems Engineering - Grundlagen und Anwendung. Orell Füssli Verlag (2012)

22. Ropohl, G.: Allgemeine Technologie - Eine Systemtheorie der Technik. Universitätsverlag Karlsruhe, Karlsruhe (2009)

23. Wirth, S.: Flexible Fertigungssysteme - Gestaltung u. Anwendung in d. Teilefertigung. VEB Verlag Technik, Berlin (1989)

24. Wirth, S., Näser, P., Ackermann, J.: Vom Fertigungsplatz zur Kompetenzzelle - Voraussetzung für den Aufbau kompetenzzellenbasierter Netze. ZWF Zeitschrift für Wirtschaftlichen Fabrikbetrieb 98, 78-83 (2003)

25. Schenk, M., Wirth, S.: Fabrikplanung und Fabrikbetrieb - Methoden für die wandlungsfähige und vernetzte Fabrik. Springer, Heidelberg (2004)

26. The Association of German Engineers (VDI): VDI 4661: Energetic characteristics - Definitions - terms - methodology. Beuth, Berlin (2003)

27. Crastan, V.: Elektrische Energieversorgung 1 - Netzelemente, Modellierung, stationäres Verhalten, Bemessung, Schalt- und Schutztechnik. Springer, Heidelberg (2012)

28. Rebhan, E.: Energiehandbuch - Gewinnung, Wandlung und Nutzung von Energie. Springer, Heidelberg (2002)

29. Rudolph, M., Wagner, U.: Energieanwendungstechnik - Wege und Techniken zur effizienteren Energienutzung. Springer, Heidelberg (2008)

30. The Association of German Engineers (VDI): VDI 4602 Part 1: Energy management Terms and definitions. Beuth, Berlin (2007)

31. Horbach, S., Ackermann, J., Müller, E., Schütze, J.: Building Blocks for Adaptable Factory Systems. Robot. Cim.-Int. Manuf. 27, 735-740 (2011)

32. Hopf, H., Müller, E.: Visualization of Energy - Energy Cards create Transparency for Energy-Efficient Factories and Processes. In: Proceedings of 23rd International Conference on Flexible Automation and Intelligent Manufacturing (FAIM), Porto (2013) 